\title{
On PIXE Analysis of Medical Samples: Thalassemia \& Wilson
}

\author{
Amir Pishkoo ${ }^{1}$ (Corresponding author), Minoo Nasiri Hamed ${ }^{2}$, Morteza Esmaeili Nojehdehi ${ }^{1}$ \\ ${ }^{1}$ Physics and Accelerators Research School, NSTRI, P.O. Box 14395-836, Tehran, Iran. \\ apishkoo@gmail.com \\ ${ }^{2}$ Amir Kabir University of Technology, Tehran, Iran. \\ minoo.nasiri@aut.ac.ir
}

\section{ABSTRACT}

The contents of six elements $(\mathrm{Cl}, \mathrm{K}, \mathrm{Ca}, \mathrm{Fe}, \mathrm{Cu}, \mathrm{Zn})$ for medical samples of 30 patients (15 with wilson's disease and 15 with Thalassemia's disease) were determined by proton induced X-ray emission (PIXE) method. In analysis of these samples, abnormal contents of $\mathrm{Cu}$ for wilson's disease and of Fe for Thalassemia's disease were observed which shows that for these cases the situation of patient's illness is very serious.

\section{Indexing terms/Keywords}

PIXE; X-ray; Thalassemia disease; Wilson disease.

\section{INTRODUCTION}

Trace elements have an important role in biological systems which in two last decades has grown rapidly. It has been demonstrated clearly that a diversity of trace elements is essential for life and a lot of effort has been put into attempts to understand the modes of action of these essential elements [2,17,18,21,22]. Knowledge of the elemental composition of some biological and medical samples is of major interest for both the basic research, and medical treatment and prophylaxis as well [1].

Qualitative and quantitative analyzes of the heavy elements in biological, medical, and environmental specimens are performed using various methods. There are destructive methods such as atomic absorption spectroscopy (AAS) [11] and inductively coupled plasma atomic emission spectroscopy [12] (or mass spectroscopy) (ICP-AES, MS) that are the most popular methods for trace element analysis. Although these methods have high sensitivity (ppm-ppb), they require a liquid specimen. Therefore, solid specimens (e.g., biological and medical tissues) should be solubilized, for example, with an acid treatment. The solubilization process decreases the concentrations of the target elements; thus, the detection of trace elements becomes more difficult [3]. Thus, elemental analysis should be performed in a non-destructive manner which is tabulated in Table 1.

Table 1. Non-destructive methods for trace element analysisable

\section{Name of analysis methods}

\author{
PIXE (Particle Induced X-ray Emission Spectroscopy) \\ NAA (neutron activation analysis) [13] \\ XRF (X-ray fluorescence spectroscopy) [3,14] \\ WDS (wavelength dispersive $x$-ray spectroscopy) [15] \\ EDS (energy dispersive x-ray spectroscopy) [16]
}

These methods provide both microscopic imaging and elemental information using emitted characteristic X-rays from the observed area.

In 1970 Johansson et al. [5,6] presented PIXE as a novel and powerful analytical method. Characteristic X rays produced in sample being irradiated by MeV protons, were for the first time detected by semiconductor $\mathrm{Si}(\mathrm{Li}) \mathrm{X}$ ray detector that had just become available. This analytical method soon became widely accepted in different accelerator laboratories, known under the acronym PIXE - particle induced X ray emission spectroscopy.

\section{SAMPLE PREPARATION}

The main objective of any preparation process is to maintain the concentration of all elements in the original sample without adding any contamination. Performing quantitative PIXE analysis of the thick targets, one should make measurements relative to a standard that has the same matrix as a measured sample. Planning to use such a technique one has to consider a proper selection of a standard. The choice of a standard for PIXE measurements is not simple and one has to consider the matrix effects as well as the possible change of an organic matrix composition during the ion beam irradiation. In our study we were using as an external standard IAEA MA-B-3/TM (fish tissue) which isconvenient for 


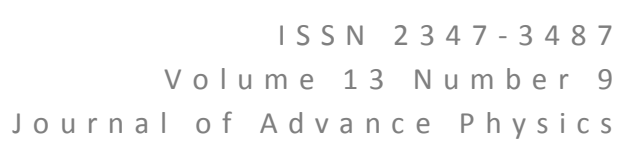

calibration aim. Its chemical matrix composition seemed to be similar to most of the investigated medical samples. All samples of type Thalassemia \& Wilson were prepared in the same way as thick targets. Not regarding the $\mathrm{Cl}$ and $\mathrm{Na}$ as favorite elements, the sample were washed out by normal saline for removal the blood and clot from the sample surface. The medical samples were put on a capton foil backing normally dried which were suspended on aluminium sample holders with holes at the center.Noting two illnesses, "Thalassemias" are autosomal recessive disorders characterised by quantitative defects in globin chain synthesis. These biosynthetic defects can be classified according to the globin chain or chains involved in deficient synthesis, common in persons of Mediterranean, African and Southeast Asian ancestry which are two forms, major \& minor [8]. "Wilson's disease" is an autosomal-recessive disorder caused by mutation in the ATP7B gene, with resultant impairment of biliary excretion of copper. Subsequent copper accumulation, first in the liver but ultimately in the brain and other tissues, produces protean clinical manifestations that may include hepatic, neurological, psychiatric, ophthalmological, and other derangements $[7,20]$.

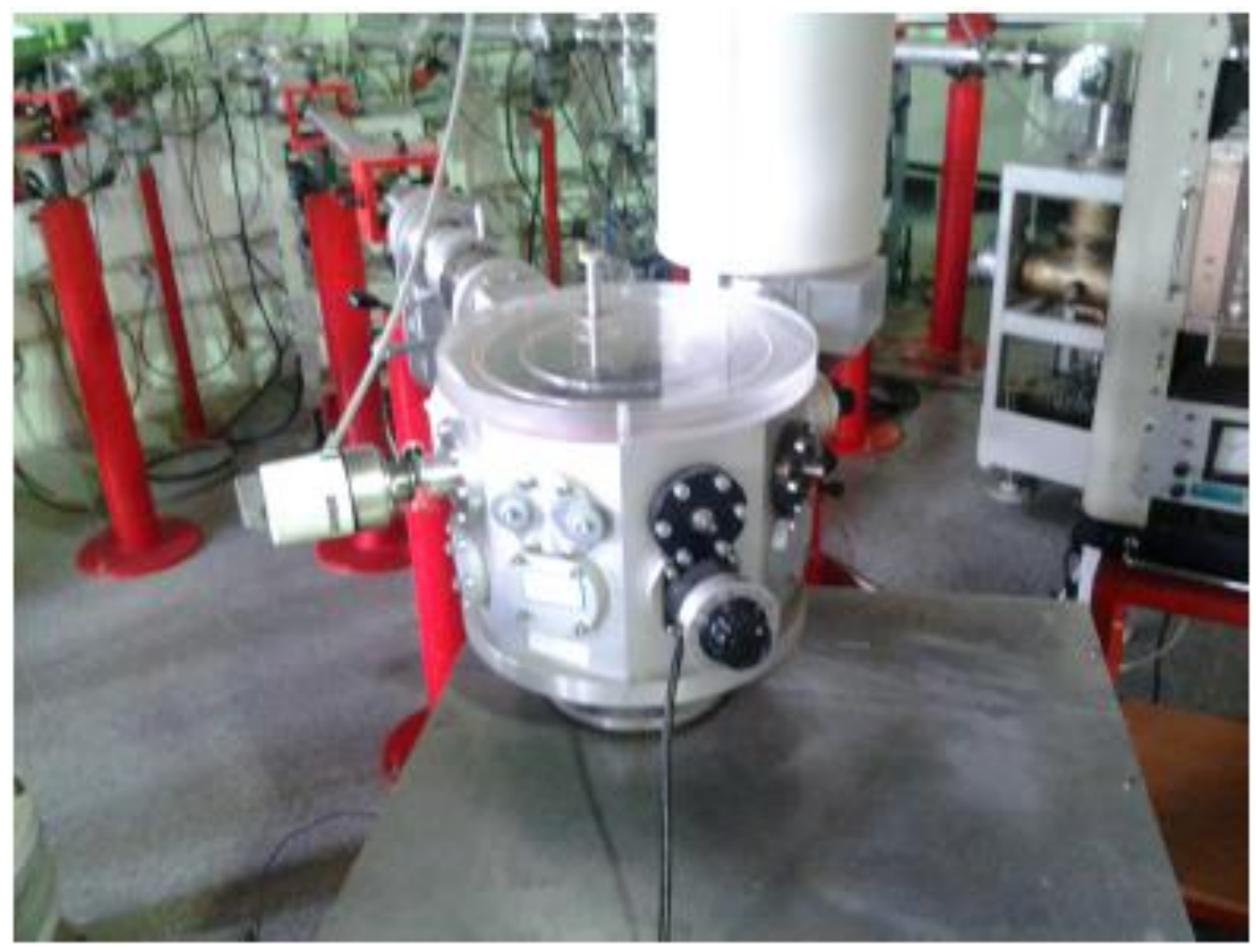

Fig 1: Schematic of the ion beam, target, and detector arrangement in the PIXE

chamber used for measurements

\section{DESCRIPTION OF A PROCEDURE}

PIXE measurements were performed at Physics and Accelerators Research School in Tehran, Iran, with the proton beam of $2 \mathrm{MeV}$ obtained from the $3 \mathrm{Mev}$ Van-de-Graff electrostatic accelerator. All the spectra were registered with a $\mathrm{Si}(\mathrm{Li})$ detector and collected by a multichannel analyzer. Characteristic X-rays are detected by $\mathrm{Si}(\mathrm{Li})$ detector placed at $135^{\circ}$. A $175 \mu \mathrm{m}$-thick Mylar absorber was positioned in front of the detector which decrease the intense low energy X-rays originating from the matrix elements. The energy resolution of the $\mathrm{Si}(\mathrm{Li})$ detector was $175 \mathrm{eV}$ for the $\mathrm{X}$-rays of $5.9 \mathrm{keV}$ $(\mathrm{Fe})$. This filter were applied in front of the detector in order to improve trace element detection and to prevent the detector from overloading with low-energy induced X-rays.

The experimental data usually is standardized before analysing. The following formula can be used to prepare standardized matrix[24-26]:

$$
Z_{i j}=\frac{X_{i j}-\overline{X_{i}}}{S_{i}}
$$

where $Z_{i j}$ are the elements of the new matrix, $X_{i j}$ the elements of the original data matrix, $\overline{\bar{X}_{i}}$ the average of elements per attribute and $S_{i}$ the standard deviation. 


$$
\begin{gathered}
\overline{X_{i}}=\frac{\sum_{j=1}^{m} X_{i j}}{m} . \\
S_{i}=\sqrt{\frac{\sum_{j=1}^{m}\left(X_{i j}-\overline{X_{i}}\right)}{m-1}} .
\end{gathered}
$$

\section{RESULTS AND DISCUSSION}

The PIXE spectrum analysis is performed by using the nonlinear least square fitting code AXIL or GUPIX [9]. Using AXIL, Fig. 1 \& Fig. 2 show typical spectrums for favorite high Z elements.

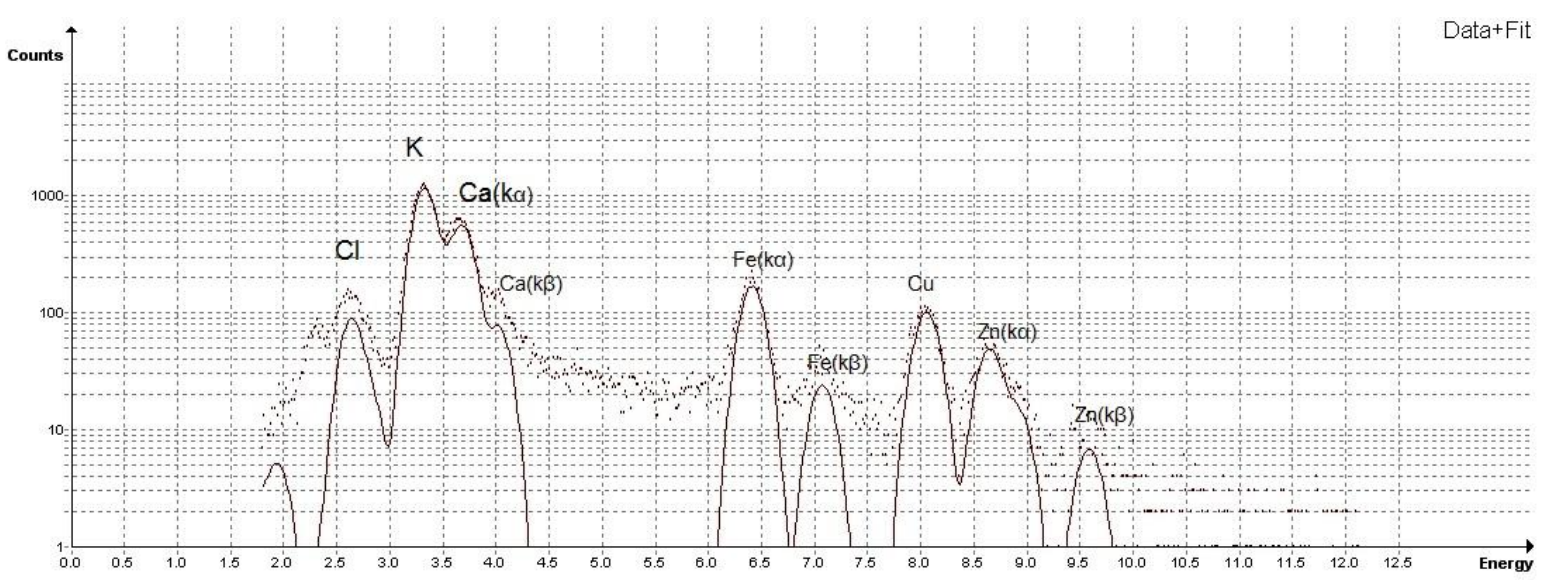

Fig 2: Typical PIXE spectrum of medical sample-Wilson (peaks of interest marked and simulated only)

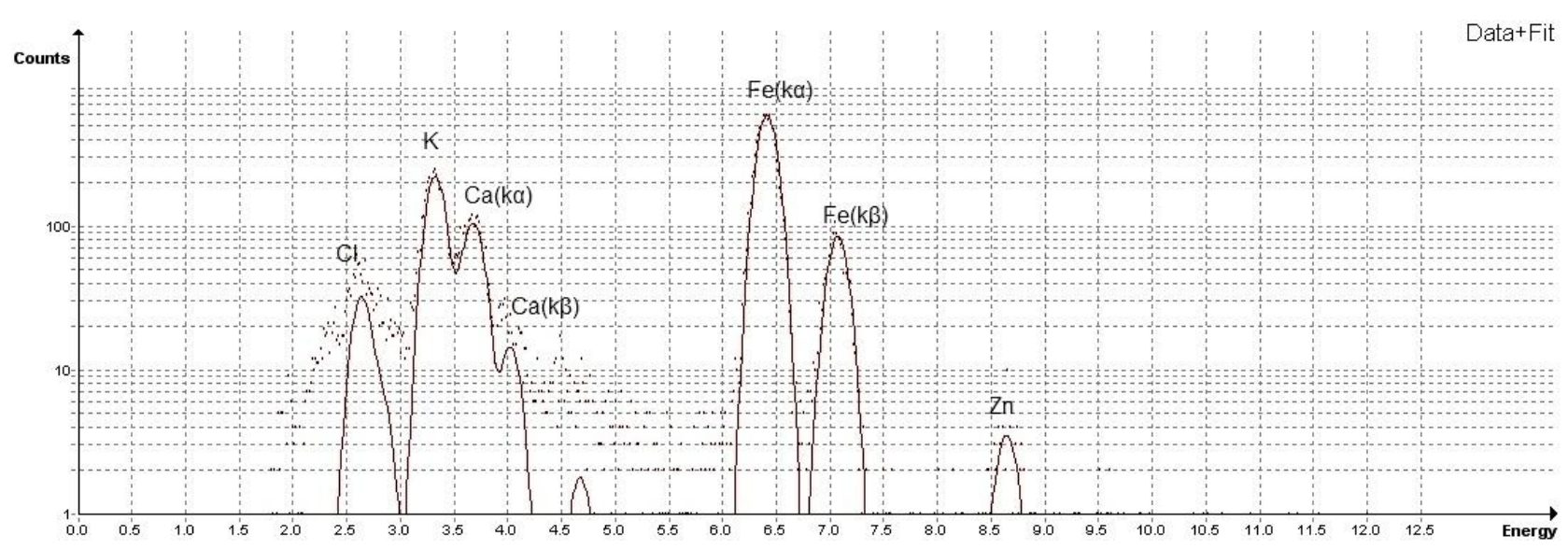

Fig 3: Typical PIXE spectrum of medical sample-Thalassemia (peaks of interest marked and simulated only)

On the basis of previous experiences for instance in [23], the contents of the six elements (see Table 2.) $\mathrm{Cl}, \mathrm{K}, \mathrm{Ca}, \mathrm{Fe}, \mathrm{Cu}$, $\mathrm{Zn}$ of the 15 patients with Wilson's disease, and of the 15 patients with Thalassemia's disease were compared. The samples were obtained by surgical operation from these patients. The results have been summarized for Wilson's disease in Table 3. and for Thalassemia's disease in Table 4., respectively. 
Table 2: Photons energies, in kev, of favorite elements

\begin{tabular}{|c|c|c|c|c|c|c|}
\hline Element & $\mathrm{K}_{\alpha 1}$ & $\mathrm{~K}_{\alpha 2}$ & $\mathbf{K}_{\beta 1}$ & $\mathrm{~L}_{\alpha 1}$ & $\mathrm{~L}_{\alpha 2}$ & $\mathrm{~L}_{\beta 1}$ \\
\hline $17 \mathrm{Cl}$ & 2.622 & 2.621 & 2.816 & & & \\
\hline $19 \mathrm{~K}$ & 3.314 & 3.311 & 3.590 & & & \\
\hline $20 \mathrm{Ca}$ & 3.692 & 3.688 & 4.013 & 341.3 & 341.3 & 344.9 \\
\hline $26 \mathrm{Fe}$ & 6.404 & 6.391 & 7.058 & 0.705 & 0.705 & 0.718 \\
\hline $29 \mathrm{Cu}$ & 8.048 & 8.028 & 8.905 & 0.9297 & 0.9297 & 0.9498 \\
\hline $30 \mathrm{Zn}$ & 8.639 & 8.616 & 9.572 & 1.0117 & 1.0117 & 1.0347 \\
\hline
\end{tabular}

As it can be seen from Table. 3, The elements $\mathrm{Cl}, \mathrm{K}, \mathrm{Ca} \& \mathrm{Fe}$ are considered as major and minor elements while the values of $\mathrm{Cu} \& \mathrm{Zn}$ shows that they are trace elements. However, the concentration values of $\mathrm{Cu}$ in samples 6,12 and 13 are very abnormal which shows that the situation of patient's illness is very serious. Numbers in "Normal Ratio" column show that concentration value of $\mathrm{Cu}$ for each case is $\mathrm{x}$ times more than normal case (fore example for sample number 12 , $x=32$ ).

Table 3: Concentration of trace elements of in 15 Wilson's patients.

\begin{tabular}{|c|c|c|c|c|c|c|c|c|}
\hline Row & Sample & $\mathrm{Cl}$ & $\mathbf{K}$ & $\mathrm{Ca}$ & $\mathrm{Fe}$ & $\mathrm{Cu}$ & $\mathrm{Zn}$ & $\begin{array}{c}\text { Normal } \\
\text { ratio }\end{array}$ \\
\hline 1 & X11177 & 1336 & 4928 & 5649 & 1894 & 16 & 114 & $\mathrm{Cu}=1$ \\
\hline 2 & X11113 & 3502 & 55906 & 1793 & 12430 & 165 & 514 & $\mathrm{Cu}=1$ \\
\hline 3 & X11112 & 4940 & 45813 & 5546 & 3319 & 86 & 581 & $\mathrm{Cu}=1$ \\
\hline 4 & X11109 & 3933 & 38388 & 1549 & 8364 & 256 & 633 & $\mathrm{Cu}=1.3$ \\
\hline 5 & X11108 & 4548 & 37731 & 4111 & 3901 & 106 & 497 & $\mathrm{Cu}=1$ \\
\hline 6 & X11107 & 1881 & 20880 & 7629 & 3138 & 2071 & 1065 & $\mathrm{Cu}=19$ \\
\hline 7 & X11096 & 18508 & 139123 & 6652 & 9971 & 267 & 2200 & $\mathrm{Cu}=1$ \\
\hline 8 & X11094 & 6950 & 24904 & 4080 & 6814 & 93 & 223 & $\mathrm{Cu}=1$ \\
\hline 9 & X11092 & 755 & 4158 & 1123 & 906 & 18 & 67 & $\mathrm{Cu}=1$ \\
\hline 10 & X11063 & 851 & 6618 & 795 & 2797 & 19 & 153 & $\mathrm{Cu}=1$ \\
\hline 11 & X11052 & 4658 & 32951 & 4070 & 3155 & 563 & 358 & $\mathrm{Cu}=3$ \\
\hline 12 & X11014 & 376 & 3322 & 250 & 149 & 555 & 171 & $\mathrm{Cu}=32$ \\
\hline 13 & X11019 & 556 & 1340 & 15227 & 1261 & 85 & 501 & $\mathrm{Cu}=12$ \\
\hline 14 & X10999 & 16806 & 79381 & 4071 & 5300 & 272 & 661 & $\mathrm{Cu}=1$ \\
\hline 15 & X11001 & 8220 & 29707 & 1535 & 10845 & 54 & 244 & $\mathrm{Cu}=1$ \\
\hline
\end{tabular}

As it can be seen from Table. 4, The elements $\mathrm{Cl}, \mathrm{K}, \mathrm{Ca} \& \mathrm{Fe}$ are considered as major and minor elements while the values of $\mathrm{Cu} \& \mathrm{Zn}$ shows that they are trace elements. However, the concentration values of $\mathrm{Cu}$ in samples 4,6,10,11,14 and 15 are very abnormal which shows that the situation of patient's illness is very serious. Numbers in "Normal Ratio" column show that concentration value of $\mathrm{Fe}$ for each case is $\mathrm{x}$ times more than normal case (for example for sample number $10, x=28$ ). 
Table 4: Concentration of trace elements of in 15 Thalassemia's patients

\begin{tabular}{|c|c|c|c|c|c|c|c|c|}
\hline Row & Sample & $\mathrm{Cl}$ & $\mathrm{K}$ & $\mathbf{C a}$ & $\mathrm{Fe}$ & $\mathrm{Cu}$ & $\mathrm{Zn}$ & $\begin{array}{c}\text { Normal } \\
\text { ratio }\end{array}$ \\
\hline 1 & X11154 & 1251 & 6508 & 6508 & 4625 & 271 & 505 & $\mathrm{Fe}=1.7$ \\
\hline 2 & X11111 & 1857 & 14195 & 14195 & 584 & 31 & 107 & $\mathrm{Fe}=0.2$ \\
\hline 3 & X11097 & 6033 & 46834 & 46834 & 2718 & 1232 & 321 & $\mathrm{Fe}=0.6$ \\
\hline 4 & X11098 & 475 & 3541 & 3541 & 1256 & 6 & 73 & $\mathrm{Fe}=13$ \\
\hline 5 & X11099 & 3190 & 31650 & 31650 & 1841 & 52 & 429 & $\mathrm{Fe}=5$ \\
\hline 6 & X11100 & 375 & 4398 & 4398 & 425 & 5 & 46 & $\mathrm{Fe}=15$ \\
\hline 7 & X11101 & 3434 & 27295 & 27295 & 1008 & 25 & 179 & $\mathrm{Fe}=0.8$ \\
\hline 8 & X11062 & 4282 & 36488 & 36488 & 3011 & 96 & 534 & $\mathrm{Fe}=8$ \\
\hline 9 & X11057 & 9618 & 69918 & 69918 & 9300 & 267 & 772 & $\mathrm{Fe}=1.5$ \\
\hline 10 & X11053 & 1143 & 14782 & 14782 & 1298 & 125 & 341 & $\mathrm{Fe}=28$ \\
\hline 11 & X11054 & 358 & 1832 & 1832 & 384 & 1 & 61 & $\mathrm{Fe}=14$ \\
\hline 12 & X11055 & 2616 & 20489 & 20489 & 2941 & 60 & 366 & $\mathrm{Fe}=5$ \\
\hline 13 & X11056 & 1332 & 12180 & 12180 & 795 & 62 & 170 & $\mathrm{Fe}=1.3$ \\
\hline 14 & X11020 & 79 & 376 & 376 & 3890 & 1 & 44 & $\mathrm{Fe}=14$ \\
\hline 15 & X11017 & 411 & 3416 & 3416 & 103 & 1 & 16 & $\mathrm{Fe}=15$ \\
\hline
\end{tabular}

\section{CONCLUSION}

This study gives information about PIXE analysis of two types of medical samples related to Wilson and Thalassemia diseases. Observed abnormalities in concentrations of $\mathrm{Cu}$ and $\mathrm{Fe}$ elements clarify a large accumulation of these elements( trace values change to minor values) in patient's body (for example in the liver). The more accumulation, the serious situation.

\section{REFERENCES}

[1] W. M. Kwiatec, J. Lekki, C. Paluszkiewicz, N. Preikschas, Nucl. Instr. Meth B 64 (1992) 512--516.

[2] R. D. Vis, C. C. A. H. Van der Stap, A. J. J. Bos, Nucl. Instr. Meth B 3 (1984) 319--325.

[3] M. Uo, T. Wada, T. Sugiama, Japanese Dental Science Review 51 (2015) 2--9.

[4] N. Hertel, Nucl. Instr. Meth B 22 (1987) 149--151.

[5] T. B., Johansson, K. R., Axelsson, S. A. E., Johansson, Nucl. Instr. and Meth. 84 (1970) 141--143.

[6] S. A. E., Johansson, T. B., Johansson, Nucl. Instr. and Meth., 137 (1975) 473--516.

[7] R. F. Pfeiffer, Wilson's disease, Seminars in neurology, Thieme Medical Publishers (2007).

[8] N. F. M. Yatim et al., Int. J. Mol. Sci. 15 (2014) 8835--8845.

[9] J. A. Maxwell, et al., Nucl. Instr. Meth B 95 (1995) 407--421.

[10] Mcmurry, Sara M., Quantum Mechanics. Addison-Wesley Publishing Company Inc. 1994.

[11] A. Kryazhov et al., Determination of $\mathrm{Au}, \mathrm{Pb}, \mathrm{Ni}$ and $\mathrm{Co}$, in Mineral raw materials by atomic absorption spectroscopy with graphite furnace, Procedia Chemistry, 10 (2014) 430--440.

[12] J. Bok-Badura et al., Spectrochimica Acta Part B: Atomic Spectroscopy, 113 (2015) 79--83.

[13] K. Prelack et al., Surgery, 133 (2003) 396--403.

[14] G. Wellenreuther et al., Spectroscopy, 63 (2008) 1461--1468. 
[15] Y. Ozdemir, et al., Applied Radiation and Isotopes, 67 (2009) 1790--1795.

[16] H. J. Jang, et al., Experimental Eye Research, 121 (2014) 58--65.

[17] A. Ochs, et al., Progress in Histochemistry and Cytochemistry, 23 (1991) 164--177.

[18] P. Dusek, et al., Progress in Histochemistry and Cytochemistry, 31 (2015) 193--203.

[19] J.M. Trocello, et al., Revue Neurologique, 169 (2013) 936--943.

[20] S. Yim, et al., Nucl. Instr. Meth B, 22 (1987) 191-192.

[21] T. P. Flaten, et al, Journal of Trace Elements in Medicine and Biology, 26 (2012) 128--130.

[22] A. Garfunkle, et al., Archives of Oral Biology, 24 (1979) 829--831.

[23] S. Vatankhah, et al, International Journal of PIXE, 7 (2007) 107--112.

[24] H. C. Romesburg, Cluster Analysis for Researchers, Life time Learninng Publications, Belmont, 1984.

[25] M. Roumie, Nucl. Instr. Meth B 227 (2005) 584--590.

[26] I. E. Kieft, et al, Nucl. Instr. Meth B 190 (2002) 492--496. 